\title{
Universitas Al Asyariah Mandar dan Perkembangannya di Polewali Mandar, 2004-2018
}

\author{
Yahdiana, Ahmadin, Muh. Rasyid Ridha \\ Prodi Pendidikan Sejarah Fakultas Ilmu Sosial Universitas Negeri Makassar \\ yahdianaa@gmail.com
}

\begin{abstract}
Abstrak
Penelitian ini bertujuan mengetahui latar belakang berdirinya Universitas Al Asyariah Mandar (UNASMAN), perkembangan UNASMAN dalam kurung waktu 2004 hingga 2018 serta Peranannya di Kabupaten Polewali Mandar.Penelitian ini bersifat deskriptik historis, dengan menggunakan metodologi sejarah yang meliputi heuristik, dalam bentuk mengumpulkan sumber sebanyak-banyaknya, kritik sumber yang bertujuan untuk menilai dan menetukan sumber, interpretasi yaitu menentukan kedudukan suatu fakta secara proposional dan historiografi atau penyajian yang merupakan pengungkapan kisah sejarah secara tertulisHasil penelitian yang menunjukkan bahwa UNASMAN didirikan karena banyaknya lulusan SMA di daerah polewali Mandar yang ingin melanjutkan sekolah ke perguruan tinggi tapi terkendala jarak, transportasi dan biaya hidup; UNASMAN dalam kurung waktu 2004-2018 telah mengalami perkembangan ini dibuktikan dengan bertambahnya jumlah mahasiswanya yang semakin meningkat, Sarana Prasarana dan juga tenaga dosennya; UNASMAN telah memberikan pengaruh yang Positif terhadap peranannya dalam pendidikan tinggi, Agama melalui pembinaan keagamaannya serta Budaya dalam pelestarian budaya lokal di Kabupaten Polewali Mandar.Berdasarkan hasil penelitian diatas disimpulkan bahwa UNASMAN mengalami perkembangan yang berlangsung dari tahun 2004-2018. Hal ini memberikan peranan besar bagi masyarakat maupun pemerintah.
\end{abstract}

\section{Kata Kunci: Unasman, Universitas, Polman}

\begin{abstract}
This study aims to determine the background of the establishment of Al Asyariah Mandar University (UNASMAN), the development of UNASMAN in the period 2004 to 2018 and its role in Polewali Mandar Regency. This research is a historical descriptive, using historical methodology which includes heuristics, in the form of gathering as many sources many, source criticism that aims to assess and determine the source, interpretation that determines the position of a fact proportionally and historiographically or is a presentation that reveals a historical story in writing. colleges but distance, transportation and living costs; UNASMAN in the period 2004-2018 has experienced this development as evidenced by the increasing number of students who are increasing, Infrastructure Facilities and also lecturers; UNASMAN has had a positive influence on its role in tertiary education, Religion through fostering religion and Culture in the preservation of local culture in Polewali Mandar Regency. Based on the above research results it was concluded that UNASMAN underwent a development that lasted from 2004-2018. This gives a big role for the community and the government.
\end{abstract}

\section{Keyword: Unasman, University, Polman}




\section{A. Pendahuluan}

Pendidikan merupakan upaya menjadi manusia agar membentuk manusia utama yang memiliki perwatakan sebagai sebagai seorang sekaligus kesatria sekaligus seorang agamawan. Pendidikan tinggi sebagai tumpuan akhir seluruh jenjang pendidikan harus menepatkan diri sebagai wahana pembentukan sarjana yang memiliki budi pekerti luhur, melangsungkan nilai-nilai kebudayaan dan memajukan kehidupan, dan membentuk satria pinandita (Harsono, 2008).

Penyelenggaran perguruan tinggi di Indonesia dilaksanakan bersama oleh pemerintah dan masyarakat. Perguruan tinggi yang diselenggarakan oleh pemerintah dikenal nama perguruan tinggi Negeri, sedangkan yang diselenggarakan oleh masyarakat dikenal dengan nama perguruan tinggi swasta. Pada saat ini Indonesia terdapat 49 perguruan tinggi negeri yang tersebar setiap ibu kota provinsi, bahkan di beberapa daerah telah tersebar sampai di ibu kota provinsi bahkan telah mencapai 1000 buah. Khusus mengenai perguruan tinggi swasta perlu ditamabahkan bahwa peneyelenggarannya haruslah ada satu badan hukum, yaitu yayasan, perkumpulan, atau badan waqaf. Dalam pada itu, mengingat luasnya penyebaran perguruan tinggi swasta. Maka sistem pembinaannya menggunakan sistem wilayah. Masing-masaing wilayah ini di bina oleh kordinator penguruan tinggi swasta (KOPERTIS). (Basir, 1992)

Perguruan tinggi harus mengambil bagian dan berpartisipasi aktif dalam pembangunan bangsa. Tridarma bidang pengabdian kepada masyarakat merupakan srategis dalam pergutaun tinggi dalam membantu pemerintah dalam mewujudkan pembangunan dan kesejahteraan bangsa. (Abbas, 2008)

Sebagai salah satu bangsa yang yang sedang membangun, maka bangsa secara umum dan Sulawesi Barat utamanya di Kabupaten Polewali Mandar secara khusus dituntut untuk senantiasa mengembangkan dan memanfaatkan ilmu pengetahuan dan teknologi dalam upaya mencapai tujuan dan cita-cita pembangunan daerah maupun bangsanya, yakni mewujudkan masyarakat yang adil dan makmur berdasarkan pancasila sejalan dengan mendirikan lembaga pedidikan dalam hal ini termasuk universitas Al Asyariah Mandar lembaga pendidikan islam. Pendidikan Islam harus mengembangkan diri untuk maju. Sesuatu yang telah dicapai saat ini secara internal dan eksternal harus di pertahankan dan dikembangkan kearah yang lebih berkualitas

Oleh karena itu konsekuensi logis dari pengembangan pendidikan khususnya pendidikan di kabuaten polewali Mandar adalah dengan jalan mendirikan lembaga pendidikan. Dalam hal ini termasuk Universitas Al Asyariah Mandar. Lembaga pendidikan tinggi ini pada dasarnya telah menunjukkan peran dan fungsinya, sekaligus kemampuannya dalam mencerdaskan kehidupan bangsa terutama di Kabupaten Polewali Mandar

Salah satu pendidikan tinggi yang berada di Sulawesi Barat yakni Universitas $\mathrm{Al}$ Asyariah Mandar yang berlokasi di Kabupaten Polewali Mandar. yang terlahir dari kegelisahan Sahabuddin melihat kondisi pendidikan di Mandar yang tertinggal, Pada saat itu banyaknya lulusan SMA asal Polewali Mandar yang ingin kuliah tapi terkendala jarak dan biaya untuk kuliah di Makassar.

STIKIP dan STIP yang berdiri sekitar tahun 1975 merupakan cikal bakal berdirinya universitas Al Syariah Mandar (UNASMAN) tahun 2004, STIKIP dan STIP digabungkan ke dalam satu lembaga yakni universitas Al Syariah Mandar yang di prakasai oleh Almarhum Sahabuddin.

Bertolak dari prinsip awal didirikannya universitas Al Asyariah Mandar oleh almarhum Sahabuddin yakni untuk masyarakat Mandar Sulawesi Barat yang seiring dengan wacana pembentukan provinsi Sulawesi Barat sebagai salah satu syarat pendiriannya telah terdapat universitas di dalamnya sehingga Universitas Al Asyariah Mandar pun segara 
didirikan atas kesadaran tersebut. Pada tahun 1975 sebagai awal sejarah cikal bakal Universitas Al Asyariah Mandar kemudian peresmiannya pun dilakukan oleh Presiden Republik Indonesia Megawati Soekarno Putri yang merupakan salah satu Perguruan Tinggi Indonesia Timur yang di resmikan langsung oleh Presiden republik Indonesia

Universitas Al Asyariah Mandar adalah salah satu komponen dunia pendidikan yang menjadi pusat keagamaan dan kebudayaan Mandar. Universitas Al Asyariah Mandar terbentuk dari dua paradigma yaitu Asyariah dan kemandaran yang bermotokan Mengabdi Untuk Semua. Akulturasi keasyariahan dan kemandaran yang konsisten dalam implementasi keprihatinnanya terhadap masyarakat Mandar yang kian bergeser, kajian agama dan kebudayaan serta kenegaraan, Ilmu umum dan Sosial lainnya akan menjadi indikator gerakan lewat penciptaan karakter Universitas $\mathrm{Al}$ Asyariah Mandar pada mulanya yakni manusia Mandar yang memahami nilai keasyariahan dan kemandaran.

Universitas Al Asyariah Mandar yang berlokasi di Kabupaten Polewali Mandar Lembaga ini adalah salah satu lembaga pendidikan pertama di Polewali Mandar dan juga lembaga pertama yang terakreditasi B di Sulawesi Barat. Lembaga Pendidikan ini penting untuk diteliti karena lembaga pendidikan ini sudah berumur dan serta telah banyak memberikan kontribusi bagi pembangunan dan peningkatan kwalitas sumber daya manusia yang berada di Sulawesi Barat

\section{B. Metode Penelitian}

Metode penelitian yang digunakan ialah kulitatif. Metode ini sering digunakan dalam ilmu sejarah dan ilmu sosil lainnya dengan tujuan untuk menumukan suatu hal yang unik dan dan mampu mengungkap peristiwa yang telah terjadi pada masa lampau. Menurut Kontowijoyo, ada lima tahapan dalam penelitian sejarah yaitu pemilihan topik, pengumpulan sumber, verifikasi sejarah, interpretasi dan penulisan. Penulisan topik berkenaan dengan alasan peneliti mengangkat topik ini. Pengumpulan sumber berkenaan dengan pengumpulan data informasi. Verivikasi kritikm sejarah berkenaan dengan pengumpulan data dan informasi. Verifikasi kritik sejarah berkenaan dengan uji keabsahan suatu sumber. Iterpretasi berkenaan dengan pencarian dan berkaitan makna antar fakta, sedangkan berkenaan dengan laporan hasil penelitian. (kuntowijoyo, 2005)

Penelitian ini adalah kajian sejarah dan tentunya dalam proses penulisannya menggunakan metode yang sesuai dengan kaidah keilmuan sejarah. Adapun tahap tahap penelitian sejarah dapat diuraikan sebagai berikut.

\section{Heuristik}

Pada tahap pertama metode penelitian sejarah seorang penulis atau peneliti harus mengumpulkan sebanyak mungkin sumbersumber sejarah guna merekosntruksi masa lalu.

Heuristik merupakan langkah awal dari metode penelitian sejarah, dimana pada tahap ini seorang peneliti mencari dan mengupayakan penemuan atas sumber sejarah yang memiliki keterkaitan dengan objek penelitian.Sumber sejarah tersebut dapat berupa catatan, tradisi lisan, dan setiap titik atau secercah apapun yang memberikan penerangan bagi cerita kehidupan masyarakat.

\section{Kritik.}

Jika sumber-sumber yang digunakan sudah dianggap cukup, langkah selanjutnya adalah menilai sumber tersebut untuk menyeleksi dan menguji kebenaran dan keabsahan suatu sumber, guna mendapatkan data yang otentik. Dalam kritik sumber, terdapat penekanan tertentu yang bertujuan untuk memberikan definisi kritik sumber itu sendiri. Tujuan dari kegiatan-kegiatan ini adalah bahwa setelah sejarawan berhasil mengumpulkan sumbersumber dalam penelitiannya, ia tidak akan menerima begitu saja apa yang tercantum dan tertulis pada sumber-sumber itu. Selanjutnya ia harus menyaringnya secara 
kritis agar terjaring fakta yang menjadi pilihannya. Langkah-langkah inilah yang disebut kritik sumber, baik terhadap bahan materi (ekstern) maupun terhadap subtansi (isi) sumber. (Syamsuddin, 2012)

\section{Interpretasi.}

Tahapan ini adalah kegiatan setelah kritik sumber. Sumber-sumber yang telah didapatkan perlu ditafsirkan oleh peneliti. Dalam tahap interpretasi, imajinasi seorang peneliti ibutuhkan untuk menafsirkan seluruh kejadian berdasarkan data yang terkumpul. Pada hakikatnya, interpretasi sejarah seringkali disbut dengan analisis data sejarah.

\section{Historiografi}

Tahap ini merupakan tahap terakhir dalam penelitian sejarah. Pada tahap ini peneliti menuliskan peristiwa sejarah tersebut dalam sebuah tulisan yang dalam penulisan, pemaparan dan pelaporan menggunakan tata cara tertentu. Dimana dalam hal ini, penelitian yang peneliti lakukan adalah penelitian dengan kajian perpustakaan dan lapangan.

\section{Pembahasan}

\section{Proses Berdirinya Universitas Al Asyariah Mandar}

\section{a. Latar Belakang Berdirinya Universitas Al Asyariah Mandar.}

Satu unsur pokok yang menjadi urusan perguruan tinggi adalah kemanusiaan mandat perguruan tinggi yang berada di tengah-tengah masyarakat adalah membantu mereka menjadi manusia dengan jati diri yang sempurna. Perguruan tinggi bukan hanya sekedar menciptakan manusia yang terlatih atau anggota masyarakat yang berpengatahuan tetapi keberadaannya mempunyai jangkauan yang jauh lebih dari itu. Perguruan tinggi mempunyai tanggung jawab untuk mengantarkan setiap anggota masyarakat agar mampu menjadi warisan dan sebuah perdaban yang menjujung tinggi harkat manusia sebagai individu dan anggota kelompok sosial. (Amir, 2016)

Salah satu pendidikan tinggi yang berada di Sulawesi Barat yakni Universitas
Al Asyariah Mandar di bawah naungan Yayasan Al Asyariah Mandar yang berlokasi di Kabupaten Polewali Mandar yang terlahir dari kegelisahan Sahabuddin melihat kondisi pendidikan di Polewali yang tertinggal Pada saat itu banyaknya lulusan SMA asal Polewali Mandar yang ingin kuliah tapi terkendala jarak dan biaya untuk kuliah di Makassar. (Hajaniah, 2019)

Selain itu adanya masyarakat Majene yang berpofesi guru yang hanya sarjana Muda (BA) dan belum sertifikasi karena syarat untuk sertifikasi harus S.1 ingin kuliah tapi tidak meninggalkan tugas pokok kemudian Mamasa dan Polewali juga mengingingkan hal tersebut dimana banyaknya pegawai-pegawai yang belum S.1 dan ingin sertifikasi. (Sarbi, 2019).

Selain itu UNASMAN pada awal berdirinya juga tidak lepas dengan Tarekat Qodiriyah, yang dimana pendirinya juga mursyid tarekat qodiriyah. Maka tujuan yang pertama pendirian UNASMAN ini ialah menjaga basis-basis jamaah tarekat qodiriyah.Dari hal tersebut maka. Sahabuddin berinisiatif untuk membangun pergurauan tinggi di Kabupaten Polewali Mandar.

Cikal bakal berdirinya UNASMAN bahwa sebelum bernama UNASMAN, masih Sekolah Tinggi Keuguruan dan Ilmu Pendidikan (STKIP) dan Sekolah Tinggi Ilmu Pertanian (STIP), kamudian digabungkan dan ditambah 6 Fakultas dan 12 Jurusan (Syibli, 2019).

Berdirinya Universitas $\mathrm{Al}$ Asyariah Mandar memiliki visi Misi yakni :

1) Visi

Terwujudnya Universitas Al Asyariah Mandar sebagai pusat pengembangan sains, teknologi yang unggul dan kompetitif dengan menjunjung tinggi nilai Keasyariahan, budaya Kemandaran. Visi tersebut sesuai dengan niat awal pendirian UNASMAN, dengan menyinergikan antara Ilmu Pengetahuan, Spiritualitas dan Kebudayaan.

2) Misi 
Universitas Al Asyariah Mandar mempunyai misi untuk melaksanakan:

a) Memperkokoh tekad untuk menjadikan nilai-nilai dan tradisi pesantren sebagai pusat keunggulan akademik dan intelektual.

b) Menanamkan nilai-nilai oral dan akhlaq mulia serta dasar-dasar spiritual, keimanan dan ketaqwaan.

c) Mengintegrasikan kembali ilmu-ilmu agama, ilmu pengetahuan dan Teknologi

d) Mengembangkan kurikulum yang adaptif dan akomodatif terhadap The Real Societal Need.

e) Kapasitas Pembangunan untuk civitas akademik

f) Kerjasama dengan Perguruan Tinggi, Baik dalam negeri ataupun Luar Negeri

Misi UNASMAN ialah langkah untuk mencapai visi. Misi tersebut untuk memperkokoh akidah dan nilai-nilai tradisi keagamaan sehingga mempunyai akhlaq yang mulia kepada siapapun. Mampu mengintegariskan nilai-nilai agama dengan Ilmu Pengetahuan dan Sains sehingga dapat mengenal Tuhan

Universitas Al Asyariah Mandar (UNASMAN) adalah salah satu Perguruan Tinggi yang terdapat di Provinsi Sulawesi Barat di Kabupaten Polewali Mandar. Yang merupakan penggabungan dari Sekolah Tinggi Keuguruan dan Ilmu Pendidikan (STKIP) dan Sekolah Tinggi Ilmu Pertanian (STIP). Untuk dapat menjalankan fungsinya profesionalnya dan akademiknya maka sekolah tinggi yang memiliki srtuktur organisasi tersendiri. Di awal terbentuknya UNASMAN yang menjadi aset UNASMAN masih sangat minim, baik dari segi Sarana dan prasarana, staf akademik, struktur organisasi juga mengalami hal serupa. UNASMAN Setelah berdiri pertama kali dipimpin oleh Rektor dan di bantu oleh 3 pembantu Rektor dimana rektor pertamanya yaitu Prof. K.H sahabuddin, pembantu rektor I Prof. Dr. Alfian Nur, pembantu rektor II Drs. H. Abdul Razak Jama dan Pembantu rektor
III Drs. H. Sukaji Sarbi dari kesemuanya itu merupakam pimpinan rektorat. Sedangkan untuk pimpinan Fakultas terdiri dari Fakultas Keguruan Dan Ilmu Pendidikan (FKIP), Fakultas Ilmu Pertanian (FIP), Fakultas Ilmu Sosial dan Ilmu Pemerintahan (FISIP), Fakultas Kesehatan Masyarakat (FKM), Fakultas Agama Islam (FAI), dan Fakultas Ilmu Komputer (FIKOM) dipimpin oleh Dekan di bantu dengan 3 pembantu Dekan.

b. Tokoh Pendiri Univeristas Al Asyariah Mandar

Universitas Al Asyariah Mandar (UNASMAN) adalah salah satu Perguruan Tinggi yang terdapat di Provinsi Sulawesi Barat. Pendiri UNASMAN ialah Sahabuddin. Salah seorang Tokoh Sufi yang juga mursyid Tarekat Qodiriyah di Sulawesi Barat, khususnya daerah Polewali Mandar dan Majene ,selain di kenal sebagai ulama tasawuf juga dikenal sebagai ulama yang perduli terhadap pendidikan. Aliran sejarah UNASMAN mustahil terpisah dari sosok bersahaja Sahabuddin sebagai tokoh sentral lahirnya UNASMAN, tanpa menafikkan peran dan andil sahabatsahabat beliau termasuk dorongan Ridwan Saleh Mattayang, dan bantuan tokoh pendidik dari Mandar dan merupakan dosen di IKIP Makassar yaitu Thahir Lopa.

2. Perkembangan Universitas Al Asyariah Mandar, dari STIKIP dan STIP ke Universitas (1975-2004)

Universitas Al Asyariah Mandar (UNASMAN) adalah salah satu Perguruan Tinggi yang terdapat di Provinsi Sulawesi Barat. Pendiri UNASMAN ialah. Sahabuddin. cikal bakal berdirinya UNASMAN bahwa sebelum bernama UNASMAN, dulunya masih Sekolah Tinggi Keuguruan dan Ilmu Pendidikan (STKIP) dan Sekolah Tinggi Ilmu Pertanian (STIP), kamudian digabungkan dan ditambah beberapa Fakultas di dalamnya.

Sahabuddin mendirikan perguruan tinggi pada tahun 1975 didirikan Sekolah Tinggi Keguruan dan Ilmu Pendidikan 
(STKIP), dimana mahasiswanya kebanyakan dari Jamaah Qadariyah yang juga berprofesi sebagai guru serta melakukan perkulihan di SD Wattang, Jalan Kemakmuran Polewali dimana waktu perkuliahan diatur secara bergantian dengan STAI.

Atas desakan Jamaah Qadariah pula untuk mendirikan perguruan tinggi sebagai tempat belajar jamaah, baik yang saat itu sudah menjadi pegawai pertanian tetapi lulusan SMA maupun yang belum menjadi pegawai negeri tetapi ingin menjadi sarjana pertanian, maka tahun 1997 didirikan pula Sekolah Tinggi Ilmu Pertanian (STIP)

Perkembangan Universitas Al Asyariah Mandar awalnya dari nama STKIP Dan STIP berubah menjadi Universitas $\mathrm{Al}$ Asyariah Mandar tahun 2004 melalui S.K Mendiknas No. 59/D/2004 tanggal 27 Dari kedua perguruan tinggi inilah ditambah 6 (enam) Program Studi dan 4 (empat) Fakultas Yayasan Al Asyariah Mandar Akte pendirian Nomor : 02 tanggal 02 September 2002 dan akhirnya berdiri Universitas Al Asyariah Mandar berdasarkan Keputusan Menteri Pendidikan Nasional Republik Indonesia Nomor : 59/D/0/2004 tentang Pendirian Universitas Al Asyariah Mandar Dan Ijin Peyelenggaraan Program Studi Yang Diselenggarakan Oleh Yayasan Al Asyariah Mandar tanggal 27 April 2004, dengan 6 (enam) Fakultas dan 12 (duabelas) Program Studi.

Setelah berhasil berpindah ke jalan Budi Utomo Manding pembangunan terus dilakukan adapun bantuan berasal dari koperties, pemerintah Daerah, Departemen Agama, Jamaah Qodariyah dan Mahasiswa..Tahun-tahun berikutnya perkembangan UNASMAN semakin memperlihatkan kemajuan yang pesat. Tepatnaya setelah menjadi Universitas yang awalnya merupakan Sekolah Tinggi Penggabungan dari STIKIP dan STIP. Seiring dengan perbaikan sarana dan prasarana kemajuan dari segi jumlah mahasiswanya juga ikut serta.
Dimulai dari kepemimpinan rektor. Chuduriah Sahabuddin, dan ketua Yayasan Muhammad Syibli Sahabuddin menunjukkan perubahan upaya mendasar menuju peningkatan kwalitas perguruan tinggi telah dimulai sejak 2010 penyehatan organisasi serta peningkatan mutu luaran (Alumnus) dan rapat kerja dilakukan kota Pare-pare tahun 2010. Sejak kepemimpinan. Chuduriah Sahabuddin dapat membuat UNASMAN terus meningkat dan dapat mengantarkan UNASMAN menjadi salah satu perguruan tinggi yang terakreditasi B oleh BAN-PT dan merupakan salah satu universitas pertama di provinsi Sulawesi Barat yang terakreditasi B (Sarbi, 2019)

\section{Peranan Universitas Al Asyariah Mandar (UNASMAN) \\ a. Bidang Pendidikan}

Mutu pendidikan tinggi merupakan kondisi dimana Perguruan Tinggi sebagai penyelenggara pendidikan mampu melaksanakan peran dan tugasnya sesuai dengan ketentuan, standar yang menjadi kebijakan makro dalam penyelenggaraan pendidikan. (Uhar, 2015)

Universitas $\mathrm{Al}$ asyariah Mandar telah menunjukkan peran yang cukup besar, dengan usaha sistem pendidikannya mereka mampu memberikan alternatif dan realita baru khususnya dalam sistem pendidikan. Keberadaan UNASMAN ini membuktikan bahwa mahasiswa yang sudah bekerja atau guru-guru maupun pegewai dapat mempercepat perbaikan nasib tanpa harus menempuh perjalanan yang terlalu jauh. dimana banyaknya masyarakat yang kuliah dan berpofesi guru yang hanya sarjana Muda (BA) dan belum sertifikasi karena syarat untuk sertifikasi harus S.1 tetap bisa kuliah tanpa meninggalkan tugas pokok karena dengan dekatnya tempat perkuliahan yang dapat di tempuh dan berada di daerah sendiri Sedangkan untuk Lulusan SMA Yang kuliah di UNASMAN dapat mengurangi biaya yang di keluarkan oleh mahasiswa karena dapat belajar di daerahnya sendiri dan tidak lagi menempuh perjalanan terlalu jauh 
Maka dapat dilihat bahwa peranan UNASMAN dalam menunjang pendidikan tinggi di Kabupaten Polewali Mandar telah berhasil terbukti banyaknya alumni yang sudah mengabdikan dirinya pada instansiinstansi baik pemerintahan maupun swasta seperti menjadi Bupati Mamasa, Sekretaris Daerah (Sekda) dan Anggota KPU. Demikian juga banyaknya alumni UNASMAN yang juga mengabdikan dirinya pada bidang pendidikan sebagai guru dan kepala sekolah di berbagai daerah Kabupaten Polewali Mandar.

\section{b. Dalam Bidang Agama}

Fungsi pembinaan keagamaan bagi mahasiswa di Perguruan Tinggi (PT) memiliki nilai strategis, karena pembinaan keagamaan merupakan upaya yang di fokuskan pada penanaman dan penguatan nilai spiritual yang mendasar dan diperlukan oleh mahasiswa dalam mewujudkan kualitas kehidupan dikampus dan kehidupan seterusnya. (Departemen, 2003)

Pembinaan keagamaan di Universitas Al Asyariah Mandar (UNASMAN) adalah upaya untuk menyeimbangkan antara kecerdasan intelektual mahasiswa dengan kecerdasan emosional dan spiritual. Senada dengan visi UNASMAN untuk menjadi pusat pengembangan sains, teknologi yang unggul dan kompetitif, menjunjung tinggi nilai Keasyariahan, budaya Kemandaran. Terdapat poin menjunjung tinggi nilai keasyariahan. Dengan demikian bahwa visi tersebut tidak hanya untuk intelektual saja, namun diimbangi dengan nilai spiritualitas yang terkandung dalam keasyariahan. Adapun tujuan UNASMAN yang menjadi hasil dari nilai spiritualitas ialah akhlaqul karimah. (Zulmaizar, 2019)

UNASMAN telah menunjukkan peran yang cukup besar, dengan usaha pembinaan keagamaannya adapun usahausaha yang di lakukan oleh UNASMAN untuk penanaman dan penguatan nilai spiritual para mahasiswa dengan cara pembinaan keagamaan. Adapun Bentuk Pembinaan yang dilakukan oleh UNASMAN yaitu Taaruf, Pengajian dan mata kuliah Agama ( Mata kuliah Al Asyariah )

\section{c. Dalam Bidang Budaya}

Dalam penamaan Universitas $\mathrm{Al}$ Asyariah Mandar menggandeng kata Mandar yang merupakan kekuatan besar sebagai upaya untuk mengangkat mandar dan manusianya menjadi malagbi dan berkualitas. Nama Universitas Al Asyariah Mandar sendiri mempunyai makna yang begitu dalam dan menunjukkan tujuan utama dari cita-cita pendirinya. Sebab Sahabuddin yang juga mursyid Tarekat Qodiriyah di Sulawesi Barat, maka terlihat ada penggabungan antara ilmu pendidikan, nilai spiritualitas dan nilai-nilai kebudayaan yang mengisi tujuan utama berdirinya UNASMAN

Adapun usaha-usaha yang di lakukan oleh UNASMAN dalam pelestarian budaya yakni didalam kurikulum baru UNASMAN diwajibkan bahwa semua prodi harus memasukkan kurikulum dalam mata kuliah Sejarah dan Kebudayaan Mandar dan itu harapakan setiap mahsiswa atau alumni harus mengetahui nilai-nilai yang termaktub dalam Kemandaran jadi nilai sakral yang ada di kemandaran itulah yang harus miliki oleh setiap mahasiswa atau alumni sehingga perlu di lestarikan dan digenerasikan bagaimana nilai kemandaran melalui satu pembelajaran mata kuliah Sejarah dan Kebudayaan Mandar oleh sebab itu didalam peranan UNASMAN melestarikan dan bagaimana mengembangkan nilai-nilai kemandaran itu dengan melalui peletarian lewat mata kuliah itu dengan 12 prodi yang ada UNASMAN sehingga di harapkan UNASMAN dapat berperan dalam melestarikan dan pengembang budaya Mandar dan nantinya berdampak dalam kehidupan sosial budaya Mandar. (Hanna, 2019). UNASMAN dapat diharapkan menjadi sumber inspirasi dapat menjadi panutan, para sumber dalam setiap event budaya mandar yang ada di kabupaten polewali mandar khususnya dan Sulawesi Barat Umumnya. Selain itu terdapat juga Unit Kegiatan Mahasiswa atau UKM Seni siin UNASMAN misalnya 
kosaster siin yang semua kegiatannya sudah berupaya dalam melestarikan tari-tari klasik mandar yang asli yaitu tari Pattudu dimana mereka sudah belajar dengan gerakangerakan asli dan pukulan-pukulan gendang yang asli yang dipelajari dan diajarkan langsung oleh guru Pattudu dan penabuh gendang yang benar itu karena UNASMAN berobsesi bahwa setiap kegiatan yang bernuagsa budaya unasman harus tampil menjadi pemicu atau menjadi contoh dan menjadi penghibur lewat seni budaya mandar yang asli dan ini sudah berjalan disetiap ada acara-acara resmi di Kabupaten Polewali Mandar Mahasiswa Kosaster UNASMAN selalu diundang dalam dikegiatan atau acara tersebut UNASMAN selau membawakan tari2 berciri khas mandar .

\section{Kesimpulan}

Data hasil penelitian, setelah melalui tahap kritik dan interpretasi, dan analisis data, maka hasil penelitian ini disimpulkan sebagai berikut: Sejarah berdirinya UNASMAN dilatarbelakangi oleh kegelisahan Sahabuddin melihat kondisi pendidikan di Polewali yang tertinggal Pada saat itu banyaknya lulusan SMA asal Polewali Mandar yang ingin kuliah tapi terkendala jarak dan biaya untuk kuliah di Makassar. Selain itu adanya masyarakat Majene yang berpofesi guru yang hanya sarjana Muda (BA) dan belum sertifikasi karena syarat untuk sertifikasi harus S.1 ingin kuliah tapi tidak meninggalkan tugas pokok

Perkembangan Universitas Al Asyariah Mandar awalnya dari nama STKIP Dan STIP berubah menjadi Universitas $\mathrm{Al}$ Asyariah Mandar tahun 2004 melalui S.K Mendiknas No. 59/D/2004

Dimulai dari kepemimpinan rektor Chuduriah Sahabuddin, M.Si dan ketua Yayasan. Muhammad Syibli Sahabuddin menunjukkan perubahan upaya mendasar menuju peningkatan kwalitas perguruan tinggi telah dimulai sejak 2010 penyehatan organisasi serta peningkatan mutu luaran (Alumnus) dan rapat kerja dilakukan kota
Pare-pare tahun 2010. Sejak kepemimpina Chuduriah Sahabuddin, dapat membuat UNASMAN terus meningkat dan dapat mengantarkan UNASMAN menjadi salah satu perguruan tinggi yang terakreditasi B oleh BAN-PT dan merupakan salah satu universitas pertama di provinsi Sulawesi Barat yang terakreditasi B

UNASMAN telah mengembangkan Kiprahnya di Wilayah Kabupaten Polewali Mandar. Hal ini cukup berarti bagi masyarakat Polewali Mandar terutama di dunia pendidikan. Hal ini dapat kita lihat dari banyaknya mahasiswanya UNASMAN yang dari kalangan pegawai pada kantorr kantor pemerintah dan swasta di Polewali Mandar dan sekitarnya yang dapat menamatkan pendidikan SI-nya di UNASMAN. Dengan tamatnya tersebut akan memberikan pengaruh yang positif bagi lingkungan dimana alumni tersebut mengabdikan dirinya sebagai pegawai khususnya yang terjun pada dunia pendidikan yaitu sebagai guru selain dari pendidikan UNASMAN juga memiliki peranan dalam bidang Agama dan budaya dimana dalam bidang agama dengan usaha pembinaan keagamaannya adapun usahausaha yang di lakukan oleh UNASMAN untuk penanaman dan penguatan nilai spiritual para mahasiswa dengan cara pembinaan keagamaan dan dalam bidang budaya UNASMAN sebagai penjaga dan perawat peradaban dan kebudayaan masyarakat Mandar.

\section{DAFTAR PUSTAKA}

Abbas, S., 2008. manajemen perguruan tinggi. jakarta: s.n.

Amir, M. f., 2016. manajemen kinerja perguruan tinggi. jakarta: s.n.

Basir, B., 1992. perguruan tinggi swasta di indonesia. jakarta: s.n.

Departemen, a. R., 2003. Pelaksanaan pendidikan Agama Islam di perguruan tinggi. jakarta: s.n.

Hajaniah, H., 2019. latar belakang berdirinya [Interview] (selasa 03 2019). 
Hanna, M., 2019. peranan unasman [Interview] (selasa 06 2019).

Harsono, 2008. Model-model pengolahan perguruang tinggi. Yogyakarta: Pustaka.

Kuntowijoyo, 2005. pengantar ilmu sejarah. yogyakarta: s.n.

Sarbi, s., 2019. perkembangan unasman [Interview] (rabu 04 2019).

Sjamsuddin, H., 2012. Metodologi Sejarah. Ombak: 2012.

Syahrizal, A., 2008. manajemen perguruantinggi. jakarta: s.n.

Syamsuddin, H., 2012. metodologi sejarah. yogyakarta: s.n.

Syibli, M., 2019. cikal bakal berdirinya [Interview] (selasa 05 2019).

Uhar, s., 2015. manajemen pendidikan perguruan tinggi. reflika aditama: s.n.

Zulmaizar, m. M., 2019. peranan unasman [Interview] (sabtu 04 2019). 